\title{
Identification of 'Chunpoong' among Panax ginseng Cultivars Using Real Time PCR and SNP Marker
}

\author{
Hua Sun, Ok Ran Lee, Yu-Jin Kim, Seok-Kyu Jeong, Jun-Gyo In, \\ Woo-Saeng Kwon, Se-Young Kim and Deok-Chun Yang* \\ Korean Ginseng Center and Ginseng Genetic Resource Bank, Kyung Hee University, \\ Seocheon, Giheung-gu Yongin-si, Gyeonggi-do 449-701, South Korea \\ (Received January 11, 2010; Revised February 19, 2010; Accepted February 23, 2010)
}

\begin{abstract}
The common DNA extraction methods are indispensable for genotyping by molecular marker analysis. However, genotyping a large number of plants is painstaking. A modified ' $\mathrm{NaOH}$-Tris' method used in this study reduces the extraction time while keeping the cost low and avoiding the use of hazardous chemicals. The endpoint analysis by realtime PCR tends to be fast and effective for the development of SNP markers linked to the 'Chunpoong' cultivar of Panax ginseng. The 'Chunpoong' marker was developed by a major latex-like protein gene sequence. From our results, we suggest that this method is successful in distinguishing 'Chunpoong' from a large number of ginseng cultivars.
\end{abstract}

Key words : Panax ginseng, chunpoong, real-time PCR, SNP

\section{INTRODUCTION}

Panax ginseng C. A. Meyer, one of the most widely used general tonic herbs, has many bioactive effects, such as adaptogen, antiaging, anti-stress, antitumor, and immunoenhancement, among others $[1,2]$. P. ginseng has been reported to contain various polysaccharides, saponins, antioxidants, peptides, and alkaloids [3, 4]. For these reasons, $P$. ginseng has been widely consumed as a health food. Few studies, however, have been performed to improve ginseng products. Having a higher content of pharmaceutical components, as well as a higher yield for this species, would be very desirable.

Plant breeders typically need to phenotype to screen large numbers of plants. Therefore, DNA needs to be extracted from large numbers of samples in order to use PCR-based markers. Hence, the objective of this research was to develop a fast, reliable, and low-cost protocol for DNA extraction suitable for PCR amplification from different plants. Recently, many rapid protocols have appeared in the literature, e.g., the IRRI [5], $\mathrm{NaOH}$-Tris [6], ultra simple [7], sarcosyl [8], Proteinase K [9, 10], chelex-100 [11], and SDS methods [12]. Currently, real-time PCR has been successfully used in numerous applications for research

* Corresponding author. E-mail: dcyang@khu.ac.kr

Phone: +82-31-201-2100, Fax: +82-31-201-2687 and diagnostics purposes. For the plant biotech industry, it represents a useful tool for the determination of copy numbers [13-14], transgenic plants [15], and single nucleotide polymorphisms (SNPs) [16, 17]. SNPs are rare, single nucleotide substitutions, and small insertion/deletion (InDel) mutations have been widely used in a variety of research areas, such as molecular markers [18], biodiversity assessment [19], and high-density genome-wide scans [20]. As a powerful tool in plant breeding, the SNP analysis technique, which can analyze any change in nucleotide sequence, allows the identification of the genotype of each plant. Among various SNP techniques, the high-resolution melting curve (HRM) is a recent advance in the detection of SNPs [21, 22].

\section{MATERIALS AND METHODS}

\section{Plant materials}

Fresh ginseng leaves were obtained from the Ginseng Genetic Resource Bank (Kyung Hee University, Korea). We used $P$. ginseng cultivars ('Chunpoong', 'Yunpoong', 'Gopoong', 'Gumpoong', 'Sunpoong', 'Sunwon', 'Sunweon', 'Sunhyang', 'Chungsun', and 'Mimaki') and a line ('86044-Hwangsook'), as well as P. quinquefolius.

\section{DNA extraction}

DNA was extracted using two different methods: 1 . 
DNA kit method: Genomic DNA was extracted from fresh leaves using the plant DNA isolation SV mini kit (GeneAll, Seoul, Korea); 2. Modified 'NaOH-Tris method' [6]: A punched section of a young leaf $(0.5 \mathrm{~cm} \times 0.5 \mathrm{~cm})$ was inserted into a $1.5-\mathrm{mL}$ tube, and $50 \mu \mathrm{L}$ of $4 \mathrm{M} \mathrm{NaOH}$ was added. The sample was homogenized until no large pieces of tissue were left by TissueLyser II (3-mm bead, 30 seconds, $30 \mathrm{~Hz}$; Qiagen, Hilden, Germany). Five microliters of homogenized product was quickly mixed with 295 $\mu \mathrm{L}$ of Tris- $\mathrm{HCl}(100 \mathrm{mM}, \mathrm{pH}$ 8.0). From this final product, $1 \mu \mathrm{L}$ was directly used for real-time PCR in a total volume of $10 \mu \mathrm{L}$ reaction volume. This gives about a 1/100 dilution from the original extract. Centrifuging was not necessary and the sample was stored at $-20^{\circ} \mathrm{C}$ if not used right away.

\section{PCR amplification}

The PCR amplifications were performed using a Corbett PCR machine (model CG1-96; Corbett Research, Sydney, Australia). PCR amplification reactions were carried out in a total volume of $20 \mu \mathrm{L}$. The mixture contained $0.5 \mu \mathrm{M}$ of each primer, $50 \mathrm{ng}$ of extracted DNA, $200 \mu \mathrm{M}$ of each dNTP, $1.5 \mathrm{mM} \mathrm{MgCl}{ }_{2}$, and one unit of DNA polymerase (EnZynomics, Daejeon, Korea). Standard PCR reaction conditions were as follows: denaturation at $94^{\circ} \mathrm{C}$ for $5 \mathrm{~min}$, followed by 35 cycles at $94^{\circ} \mathrm{C}$ for 30 seconds, $58^{\circ} \mathrm{C}$ for 30 seconds, and $72^{\circ} \mathrm{C}$ for 30 seconds, and a final 7 -minute extension at $72^{\circ} \mathrm{C}$.

\section{Real-time PCR amplification}

Real-time PCR was performed with a Rotor-Gene 6000 (Corbett Life Science). The reaction mixture contained 24 ng of DNA, $5 \mu \mathrm{M}$ of each primer (181F: 5'-GGCTCGATATATGTACGTAC-3'/TSP2R: 5'-CCACCTGCACCATAAGTGACAA-3'), $100 \mu \mathrm{M}$ of each dNTP, $1.5 \mathrm{mM}$ $\mathrm{MgCl}_{2}, 2 \times$ mastermix (SensiMixPlus SYBR; Quantace Ltd.,
London, UK), and $0.4 \mathrm{uL}$ of Eva Green in a total volume of $10 \mu \mathrm{L}$. The following PCR cycle profile was as follows: $10 \mathrm{~min}$ of an activation period at $95^{\circ} \mathrm{C}$, followed by 45 cycles of a three-step thermal profile involving $10 \mathrm{sec}-$ onds at $95^{\circ} \mathrm{C}$ for denaturation, $15 \mathrm{sec}$ at $59^{\circ} \mathrm{C}$ for combined annealing, and $20 \mathrm{sec}$ at $72^{\circ} \mathrm{C}$ for extension. (The Green channel setting was 'On.') The melt analysis conditions consisted of a ramp from $70^{\circ} \mathrm{C}$ to $80^{\circ} \mathrm{C}$, rising by $1^{\circ} \mathrm{C}$ at each step. For the data analysis, the endpoint analysis method was used to identify the 'Chunpoong' cultivar of $P$. ginseng. Endpoint analysis is a technique that allows the amplified samples to be discriminated from non-amplifying samples at the end of a run. Endpoint analysis results were described as 'Reaction' or 'No Reaction' in automated tables.

\section{RESULTS AND DISCUSSION}

In this study, DNA extraction by the $\mathrm{NaOH}$-Tris method and endpoint analysis by real-time PCR using SNP primers were applied to the identification of the ginseng line 'Chunpoong' among a large number of ginseng cultivars. To analyze a large number of cultivars, we used the leafpunch method and $\mathrm{NaOH}$-Tris technique for preparing DNA (described in the Materials and methods). This method is fast, low cost, and a simple way to analyze a large number of samples.

The molecular marker for 'Chunpoong' was developed based on a DNA walking sequence of the major latex-like protein (MLP) gene [23]. The downstream 181-bp fragment was amplified only in 'Chunpoong,' whereas a 321bp fragment was widely amplified in all other cultivars (universal sequence) [23]. The alignment results show a 4-bp insertion site in the 181-bp sequence, which was used to design a 'Chunpoong'-specific primer (181F) (Fig. 1).

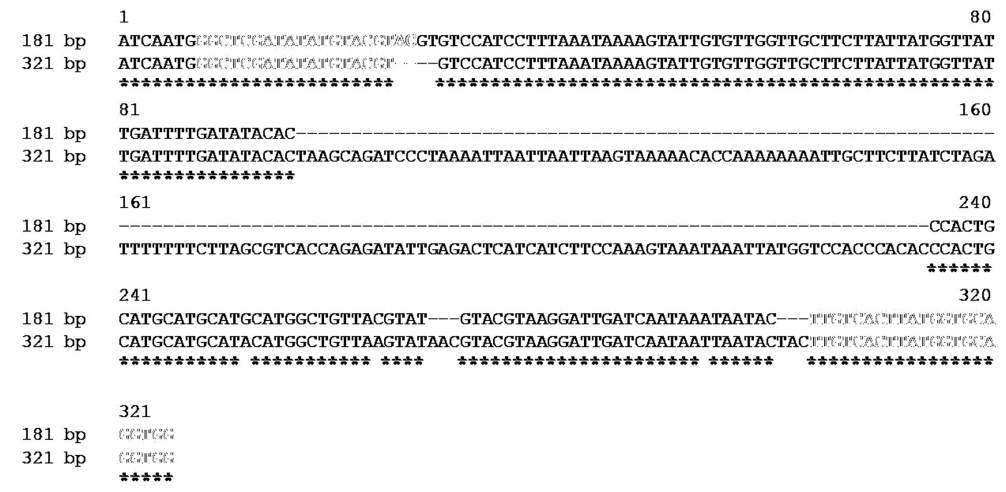

Fig. 1. The sequence alignments of the 181- and 321-bp fragments. The alignment program used in this analysis was Kalign 2.0 (www.ebi.ac.uk/Tools/kalign/index.html). The SNP primer location is indicated by gray-colored base pairs. 

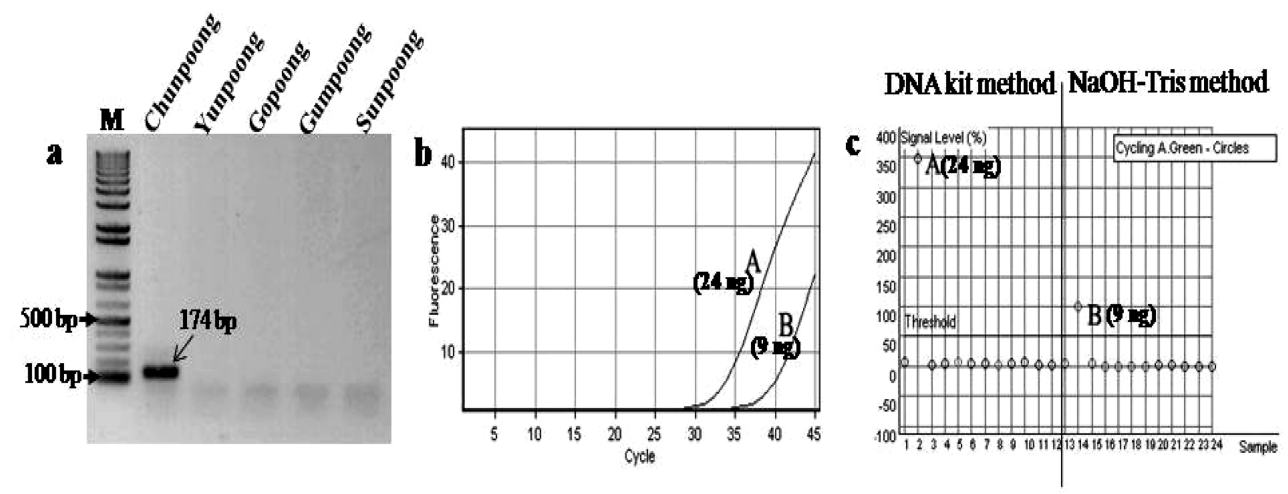

Fig. 2. Comparison of the PCR-based and real-time PCR of the 'Chunpoong' positive marker. a Agarose gel photo of the 174-bp fragment associated with the 'Chunpoong' specific marker based on PCR. b and c Amplification of DNA by Eva Green-based real-time PCR using the 181F/TSP2R primers from 12 different ginseng samples, including $P$. ginseng cultivars ('Chunpoong', 'Yunpoong', 'Gopoong', 'Gumpoong', 'Sunpoong', 'Sunwon', 'Sunweon', 'Sunhyang', 'Chungsun', and 'Mimaki'), a line ('86044-Hwangsook'), and P. quinquefolius. b Continuous monitoring of fluorescence emission during rapid cycle PCR. Template DNA from two different extraction methods are indicated (A and B). c Graphic of endpoint analysis.

Table 1. The Panax species used in this study

\begin{tabular}{|c|c|c|c|c|}
\hline \multirow{2}{*}{\multicolumn{2}{|c|}{ Cultivar/Line }} & \multirow{2}{*}{ Classification } & \multicolumn{2}{|c|}{ Real-time PCR (Endpoint analysis) } \\
\hline & & & Kit & $\mathrm{NaOH}-\mathrm{Tris}$ \\
\hline \multirow[t]{11}{*}{$P$. ginseng } & Chunpoong & Korean cultivar & Reaction & Reaction \\
\hline & Yunpoong & Korean cultivar & No Reaction & No Reaction \\
\hline & Gopoong & Korean cultivar & No Reaction & No Reaction \\
\hline & Gumpoong & Korean cultivar & No Reaction & No Reaction \\
\hline & Sunpoong & Korean cultivar & No Reaction & No Reaction \\
\hline & Sunwon & Korean cultivar & No Reaction & No Reaction \\
\hline & Sunweon & Korean cultivar & No Reaction & No Reaction \\
\hline & Sunhyang & Korean cultivar & No Reaction & No Reaction \\
\hline & Chungsun & Korean cultivar & No Reaction & No Reaction \\
\hline & 86044-Hwangsook & Korean variety & No Reaction & No Reaction \\
\hline & Mimagi & Japanese cultivar & No Reaction & No Reaction \\
\hline \multicolumn{2}{|c|}{ P. quinquefolius } & American accession & No Reaction & No Reaction \\
\hline
\end{tabular}

To determine the specificity of the marker, PCR-based analysis was performed. The 174-bp fragment represented the AG insertion in 'Chunpoong,' and it was amplified with a primer combination of $181 \mathrm{~F}$ and TSP2R (Fig. 2a). To test the specificity of the marker in real-time PCR, 12 different ginseng samples were used. Fig. $2 \mathrm{~b}$ and $2 \mathrm{c}$ are shown within the range of $9 \mathrm{ng}$ to $24 \mathrm{ng}$. The detection of a rise in fluorescence due to DNA amplification was correlated with DNA template concentration. No amplified products were observed in any of the samples, except 'Chunpoong' (Fig. 2b and 2c). Endpoint analysis is simple and easy to understand because the result table is automatically generated and positive and negative reactions are indicated as 'Reaction' and 'No Reaction', respectively (Table 1).
In conclusion, we demonstrated a low-cost and rapid method to distinguish 'Chunpoong' from a large number of ginseng cultivars. In June 2008, based on this method, we successfully selected 'Chunpoong' from among 8,200 cultivars in a ginseng field. We anticipate that this method will be useful for other plant breeding programs.

\section{ACKNOWLEDGEMENTS}

This study was supported by KGCMVP (Korean Ginseng Center for Most Valuable Products \& Ginseng) for Technology Development Program of Agriculture and Forestry, Ministry for Food, Agriculture, Forestry and Fisheries, Republic of Korea. 


\section{REFERENCES}

1. Banerjce U, Izquierdo JA. Antistress and antifatigue properties of Panax ginseng: Comparison with piracetan. Acta Physiol Lat Am. 32: 277-285 (1982)

2. Sugaya A, Yuzurihara M, Tsuda T, Yasuda K, Kajiwara K, Sugaya E. Proliferative effect of ginseng saponin on neurite extension of primary cultured neurons of the rat cerebral cortex. J Ethnopharmacol. 22: 173-181 (1998)

3. Jo JS, Han YN, Oh HI, Park H, Sung HS, Park JI. Korean ginseng has a characteristic shape. In: Han YN, Oh HI, Park H, Sung HS, Park JI (ed), Understandiny of Korean ginseng, The Society for Korean Ginseng, Hanrimwon, Seoul, p 3738 (1995)

4. Palazon J, Cusido R M, Bonfil M, Mallol A, Moyamo E, Marales C, Pinol MT. Elicitation of different Panax ginseng transformed root phenotypes for an improvement ginsenoside production. Plant Physiol Biochem. 41: 1019-1025 (2003)

5. Zheng K, Subudhi PK, Domingo J, Maopantay G, Huang N. Rapid DNA isolation for marker assisted selection in rice breeding. Rice Genet Newslett. 12: 48 (1995)

6. Wang H, Qi M, Cutler AJ. A simple method of preparing plant samples for PCR. Nucleic Acids Res. 21: 4153-4154 (1993)

7. Ikeda N, Bautista NS, Yamada T, Kamijima O, Ishii, T. Ultrasimple DNA extraction method for marker-assisted selection using microsatellite markers in rice. Plant Mol Biol Rep. 19: 27-32 (2001)

8. Cheung WY, Hubert N, Landry BS. A simple and rapid DNA microextraction method for plant, animal, and insect suitable for RAPD and other PCR analyses. PCR Methods Appl. 3: 69-70 (1993)

9. Guidet F. A powerful new technique to quickly prepare hundreds of plant extracts for PCR and RAPD analyses. Nucleic Acids Res. 22: 1772-1773 (1994)

10. Dilworth E, Frey JE. A rapid method for high throughput DNA extraction from plant material for PCR amplification. Plant Mol Biol Rep. 18: 61-64 (2000)

11. Chunwongse J, Martin GB, Tanksley SD. Pre-germination genotypic screening using PCR amplification of half-seeds. Theor Appl Genet. 86: 694-698 (1993)

12. Do N, Adams RP. A simple technique for removing plant polysaccharide contaminants from DNA. Biotechniques 10: 162-6 (1991)

13. Callaway AS, Abranches R, Scroggs J, Allen GC, Thompson WF. High-throughput transgene copy number estimation by competitive PCR. Plant Mol Biol Rep. 20: 265-277 (2002)

14. Joshi MU, Pittman HK, Haisch CE, Verbanac KM. Real-time PCR to determine transgene copy number and to quantitate the biolocalization of adoptively transferred cells from EGFP-transgenic mice. Biotechniques 45: 247-258 (2008)

15. Dalla CL, Vaccari I, Mandolini M, Martinelli L. Elaboration of a Reliable Strategy Based on Real-Time PCR To Characterize Genetically Modified Plantlets and To Evaluate the Efficiency of a Marker Gene Removal in Grape (Vitis spp.). J Agric Food Chem. 57: 2668-2677 (2009)

16. Wu SB, Wirthensohn MG, Hunt P, Gibson JP, Sedgley M. High resolution melting analysis of almond SNPs derived from ESTs. Theor Appl Genet. 118: 1-14 (2008)

17. Mader E, Lukas B, Novak JA. Strategy to setup codominant microsatellite analysis for high-resolution-melting-curve-analysis (HRM). BMC Genet. 9: 69 (2008)

18. Garces-Claver A, Fellman SM, Gil-Ortega R, Jahn M, ArnedoAndres MS. Identification, validation and survey of a single nucleotide polymorphism (SNP) associated with pungency in Capsicum spp. Theor Appl Genet. 115: 907-916 (2007)

19. van Tienderen PH, de Haan AA, van der Linden CG, Vosman B. Biodiversity assessment using markers for ecologically important traits. Trends Ecol Evol. 17: 577-582 (2002)

20. Ohnishi Y, Tanaka T, Ozaki K, Yamada R, Suzuki H, Nakamura Y. A high-throughput SNP typing system for genomewide association studies. J Hum Genet. 46: 471-477 (2001)

21. Shiokai S, Kitashiba H, Shirasawa K, Nagano K, Nishio T. Leaf-punch method to prepare a large number of PCR templates from plants for SNP analysis. Mol Breeding 23:329336 (2009)

22. Garritano S, Gemignani F, Voegele C, Nguyen-Dumont T, Le Calvez-Kelm F, De Silva D, Lesueur F, Landi S, Tavtigian $\mathrm{SV}$. Determining the effectiveness of high resolution melting Analysis for SNP genotyping and mutation scanning at the TP53 locus. BMC Genet. 10: 5 (2009)

23. Sun H, Kim MK, Pulla RK, Kim YJ, Yang DC. Isolation and expression analysis of a novel major latex-like protein (MLP151) gene from Panax ginseng. Mol Biol Report, Online published (2009) 